\title{
Evidence for Altered Synthesis of Type II Collagen in Patients with Osteoarthritis
}

\author{
Fred Nelson, Leif Dahlberg, Sheila Laverty, ${ }^{\star \ddagger}$ Agnes Reiner, ${ }^{*}$ Isabelle Pidoux, ${ }^{*}$ Mirela lonescu, ${ }^{\star}$ Graeme L. Fraser, ${ }^{\star}$ \\ Emerson Brooks, ${ }^{\S}$ Michael Tanzer, ${ }^{\S}$ Lawrence C. Rosenberg, $\|$ Paul Dieppe, ${ }^{\complement}$ and A. Robin Poole* \\ *Joint Diseases Laboratory, Shriners Hospitals for Children, Division of Surgical Research, Department of Surgery, McGill University,

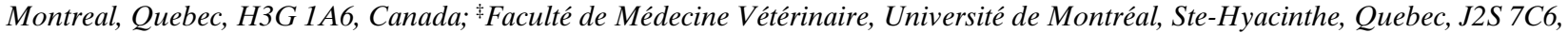 \\ Canada; ${ }^{\S}$ Division of Orthopaedics, Department of Surgery, Montreal General Hospital, McGill University, Montreal, Quebec, H36 1A6, \\ Canada; "Orthopaedic Research Laboratories, Montefiore Hospital and Medical Center, Bronx, New York 10467; "IDepartment of \\ Rheumatology, University of Bristol Medical School, Bristol Royal Infirmary, Bristol BS2 8HW, United Kingdom
}

\begin{abstract}
There is evidence to suggest that the synthesis of type II collagen is increased in osteoarthritis (OA). Using an immunoassay, we show that the content of the C-propeptide of type II procollagen (CPII), released extracellularly from the newly synthesized molecule, is directly related to the synthesis of this molecule in healthy and osteoarthritic articular cartilages. In OA cartilage, CPII content is often markedly elevated (mean 7.6-fold), particularly in the mid and deep zones, reaching $29.6 \%$ of the content in newborn. Synthesis is also directly related to total collagen II content in OA, suggesting its importance in maintaining collagen content and cartilage structure. The release of CPII from cartilage is correlated directly with cartilage content. However, the increase in CPII in OA cartilage is not reflected in serum, where a significant reduction is observed. Together these studies provide evidence for alterations in procollagen II synthesis in vivo in patients with OA. (J. Clin. Invest. 1998. 102:2115-2125.) Key words: cartilage • osteoarthritis • collagen • synthesis $\bullet$ immunoassay
\end{abstract}

\section{Introduction}

Type II collagen is the main component of cartilage, comprising $15-25 \%$ of the wet weight, approximately half the dry

P. Dieppe and A.R. Poole are equal senior authors.

A preliminary report of part of this study was presented as an abstract at the Trans. 40th Annual Meeting of the Orthopaedic Research Society in 1994.

Address correspondence to Dr. A.R. Poole, Joint Diseases Laboratory, Shriners Hospitals for Children, Division of Surgical Research, Department of Surgery, McGill University, 1529 Cedar Avenue, Montreal, Quebec, H36 1A6, Canada. Phone: 514-849-6208; FAX: 514-849-9684; E-mail: rpoole@shriners.mcgill.ca F. Nelson's current address is Orthopaedics Medical Group of San Diego, 7910 Frost St., Suite 202, San Diego, CA 92123. J.L. Dahlberg's current address is Department of Orthopaedics, University Hospital MAS, Malmö, Sweden. E. Brooks' current address is Queen Elizabeth Hospital, Riverside Dr., Charlottetown, P.E.I., C1A 8T5 Canada. P. Dieppe's current address is MRC Health Services Research Collaboration, University of Bristol, Bristol, BS8 2PR, United Kingdom.

Received for publication 7 August 1998 and accepted in revised form 22 October 1998.

J. Clin. Invest.

(C) The American Society for Clinical Investigation, Inc. 0021-9738/98/12/2115/11 \$2.00

Volume 102, Number 12, December 1998, 2115-2125

http://www.jci.org weight (1), and representing 90-95\% of the total collagen content of this tissue $(2,3)$. It forms fibrils that endow cartilage with tensile strength $(4,5)$.

The fibrillar collagens (types I, II, and III) are synthesized as procollagen $\alpha$ chains (6). The procollagen molecule is secreted from the cell into the extracellular matrix where it forms fibrils. This is accompanied by the removal of the $\mathrm{C}$ - and $\mathrm{N}$-propeptides, by specific $\mathrm{C}$ - and $\mathrm{N}$-proteinases, as collagen fibrils are formed (7).

Three identical 35-kD chains, covalently bonded by interchain disulfide bonds, comprise the C-propeptide of type II procollagen (CPII) $)^{1}$ procollagen, within 15 min of labeling (8); it can be detected immunohistochemically in the extracellular matrix of cartilage (9) in association with collagen fibrils (10). It represents a potential marker of type II procollagen synthesis in vivo as well as in vitro. An immunoassay for the C-propeptide of type II procollagen has been developed (11) and used to study its content in growth plate cartilages (12) and in the circulation of patients with rheumatoid arthritis where its content is increased (13). Newly synthesized type II procollagen and the removal of the CPII (by C-proteinase activity) can also be studied by immunobinding of radiolabeled molecules and SDS-PAGE/autoradiography (8) and by immunoblotting (14). In view of the fact that the majority (90-95\%) of cartilage collagen (by mass) is type II collagen, and hydroxyproline is predominantly concentrated in this molecule (representing $9.9 \%$ of the total amino acid composition of the molecule [15]), incorporation of ${ }^{3} \mathrm{H}$-proline into ${ }^{3} \mathrm{H}$-hydroxyproline can be used to study type II procollagen synthesis by using anion exchange chromatography to separate radiolabeled hydroxyproline from radiolabeled proline fractions (16-18). Although this method is accurate, it is very cumbersome and can usually only be used to analyze synthesis in vitro, which, because of environmental differences, may not accurately reflect synthesis in vivo. We sought to establish whether the content of CPII could be used as an index of the synthesis of this molecule. A good correlation would mean that its measurement by immunoassay, even in frozen cartilage, could provide a convenient analysis of procollagen II synthesis in vivo (not previously possible), as well as in vitro. This correlation would likely depend on a relatively short half-life for CPII.

The survival of the extracellular matrix of cartilage depends on a balance between synthesis and degradation of key matrix molecules such as type II collagen. In osteoarthritis (OA), where degeneration of articular cartilage is an underly-

1. Abbreviations used in this paper: CHAPS, 3-(3-[(cholamidopropyl)dimethylammonio]-1-propanesulfonate); CPII, C-propeptide of type II procollagen; IGF-1, insulin-like growth factor; OA, osteoarthritis; SF, synovial fluid. 
ing feature of the condition, there is limited evidence for increased synthesis of collagen in early degeneration $(19,20)$ as well as of proteoglycan $(21,22)$. Analyses of mRNA, by in situ hybridization, have also pointed to an activation of type II procollagen expression in this human disease $(23,24)$. The degeneration of articular cartilage in $\mathrm{OA}$ is accompanied by increased damage to type II collagen $(3,25)$ that involves enhanced collagenase activity (26). This starts at and close to the articular surface and extends progressively, with increasing degeneration, into the middle and deep zones $(3,27)$. The large proteoglycan aggrecan is also lost wherever type II collagen damage is most pronounced (27). These changes lead to a net loss of type II collagen (3) and of the proteoglycan aggrecan $(21,22)$.

In this article, we show that by measuring CPII, we can now measure and study type II procollagen synthesis in human cartilages in vitro and in vivo. These observations confirm and extend evidence for the increased synthesis in OA articular cartilage and demonstrate the potential for repair of this molecule in articular cartilage, in OA. Studies of circulating CPII in serum indicate that this increase in type II procollagen synthesis in OA cartilage is not reflected systemically.

\section{Methods}

\section{Subjects}

After obtaining local ethics committee approval for the study, we collected serum samples from 93 ambulatory subjects attending a blood donor center, none of whom had any evidence of arthritis or any other inflammatory disease. This group comprised 52 women and 41 men (Table I). Serum and synovial fluid (SF) samples were also collected without anticoagulant, from patients with knee arthritis requiring withdrawal of SF for diagnostic or therapeutic reasons. The serum samples were collected at the same time that the joint was aspirated. Patients were excluded if they had had a steroid injection into the index knee joint within 3 mo of the study; other therapy was not taken into account. There were 56 patients with active RA and synovitis of the knees ( 36 women and 20 men [Table I]) and 59 patients with OA of the knee and an effusion (43 women and 16 men [Table I]). All patients had been referred to the Department of Rheumatology at the Bristol Royal Infirmary; RA was diagnosed by American College of Rheumatology criteria (28) and OA on the basis of use-related pain in the index joint, combined with radiological features of OA, including definite joint space narrowing.

SFs were centrifuged at $200 \mathrm{~g}$ for $10 \mathrm{~min}$, and the supernatants were frozen at $-70^{\circ} \mathrm{C}$ before analysis. Analyses of SF and recording of other clinical parameters were as described (29).

Table I. Details of Human Subjects Who Were Examined for the Concentration of CPII in Their Body Fluids

\begin{tabular}{lccc}
\hline Age $(\mathrm{yr})$ & Controls & OA & RA \\
\hline $20-30$ & - & - & $3(2 \mathrm{~F}, 1 \mathrm{M})$ \\
$30-40$ & $2(1 \mathrm{~F}, 1 \mathrm{M})$ & - & $2(1 \mathrm{~F}, 1 \mathrm{M})$ \\
$40-50$ & $24(13 \mathrm{~F}, 11 \mathrm{M})$ & $7(4 \mathrm{~F}, 3 \mathrm{M})$ & $3(1 \mathrm{~F}, 2 \mathrm{M})$ \\
$50-60$ & $21(12 \mathrm{~F}, 9 \mathrm{M})$ & $16(12 \mathrm{~F}, 4 \mathrm{M})$ & $17(10 \mathrm{~F}, 7 \mathrm{M})$ \\
$60-70$ & $22(12 \mathrm{~F}, 10 \mathrm{M})$ & $15(10 \mathrm{~F}, 5 \mathrm{M})$ & $22(14 \mathrm{~F}, 8 \mathrm{M})$ \\
$70-80$ & $10(6 \mathrm{~F}, 4 \mathrm{M})$ & $17(13 \mathrm{~F}, 4 \mathrm{M})$ & $8(7 \mathrm{~F}, 1 \mathrm{M})$ \\
$80-90$ & $14(8 \mathrm{~F}, 6 \mathrm{M})$ & $4(4 \mathrm{~F})$ & $1(1 \mathrm{~F})$ \\
Total & $93(52 \mathrm{~F}, 41 \mathrm{M})$ & $59(43 \mathrm{~F}, 16 \mathrm{M})$ & $56(36 \mathrm{~F}, 20 \mathrm{M})$ \\
& & &
\end{tabular}

F, female; M, male.

\section{Cartilages}

Human fetal knee articular/epiphyseal cartilages were obtained from nine therapeutic abortions (at 16-18 wk) and two stillbirths. Human articular cartilages, macroscopically normal in appearance, from adult femoral condyles were obtained at autopsy within $16 \mathrm{~h}$ of death (41-81 yr). These persons had not received chemotherapy and did not include those who suffered from diabetes. The same sites where cartilage remained in patients at arthroplasty for OA of the knee (50-80 yr) were also studied. Osteophytic cartilages were not examined.

All adult human cartilages were histologically graded by the method of Mankin et al. for degenerative changes (19). For further details see Rizkalla et al. (22).

Fetal bovine articular/epiphyseal cartilages were isolated from 163-180-d gestation fetuses from a local abattoir. The ages were determined from a veterinary formula based upon measurements of tibial length (30).

\section{Materials}

GIBCO BRL (Burlington, Ontario, Canada) Dulbecco's modified Eagle's medium (DMEM) was from Life Technologies (Grand Island, NY). Tritiated proline and L- $\left.{ }^{35} \mathrm{~S}\right]-$ methionine were from Amersham (Oakville, Ontario, Canada). Human recombinant insulin (porcine pancreas) and pepstatin A was from Sigma (St. Louis, MO). Insulin-like growth factor-1 (IGF-1, $2 \mathrm{mg} / \mathrm{ml}$ in water) was a gift from Dr. A. Skottner (Pharmacia-Upjohn, Stockholm, Sweden). Protein A-Sepharose CL-4B was purchased from Pharmacia-Upjohn (Toronto, Ontario, Canada). Resin AG 50W 8× 200-400 m was supplied by Bio-Rad (Mississauga, Ontario, Canada).

\section{Cartilage preparation, culture, and biolabeling of collagen}

Bovine studies. Fetal bovine femoral condylar articular/epiphyseal cartilage was used at a stage when there is no significant epiphyseal center of ossification. 6-mm diameter cartilage plugs were cut to a depth of $1 \mathrm{~cm}$ with a stainless steel punch and maintained in Eagle's DMEM (see below) containing $50 \mathrm{mM}$ Hepes buffer. Starting from the articular surface, 1-mm thick discs were isolated using a razor blade in conjunction with a special plastic cutting jig. In view of tissue heterogeneity, each of eight discs was divided into 16 wedges of equal size, and two pieces of each disc were apportioned to each of eight separate wells of 24-well Falcon 3047 plates (Becton Dickinson, Lincoln Park, NJ). Thus, each of the wells received a total of 16 pieces of cartilage in $1 \mathrm{ml}$ culture medium. Larger well numbers were created in the same manner. The total wet tissue weight per well, at the time of harvest, was recorded after removal of excess fluid. It was between 40 and $60 \mathrm{mg}$ (mean $50 \mathrm{mg}$ ). Quadruplicate wells were studied for each experimental point.

In all explant experiments, the freshly isolated cartilage was washed for $10 \mathrm{~min}$ in $2.5 \mathrm{mg} / \mathrm{ml}$ amphotericin B (fungizone) followed by amphotericin B plus 10 times the normal concentration of penicillin and streptomycin (see below), before being washed with standard serum-free culture medium. The culture medium was Eagle's DMEM with penicillin $(100 \mathrm{U} / \mathrm{ml})$, streptomycin $(100 \mu \mathrm{g} / \mathrm{ml}), 50 \mathrm{mM}$ Hepes buffer, $\mathrm{pH} 7.4$, bovine serum albumin $(100 \mu \mathrm{g} / \mathrm{ml})$, and fresh ascorbic acid $(50 \mu \mathrm{g} / \mathrm{ml})$. Media were changed every $2 \mathrm{~d}$ and frozen before assay.

To establish steady state tissue turnover, explants in all 24 wells were maintained in the standard serum-free culture medium for $10 \mathrm{~d}$. Tritiated proline was then added for a further $2 \mathrm{~d}$ with $0,12.5,25,50$, 100 , and $200 \mathrm{ng}$ IGF- $1 / \mathrm{ml}$.

In studies of the relationship of CPII content in bovine cartilage to the release of CPII into culture media, conditions were as described except for the following exceptions. Cartilages were first maintained in standard serum-free culture medium for $6 \mathrm{~d}$. This was followed by the addition of a mixture of insulin (I), selenium (S), and transferrin (T) (10:10:0.01) at 5, 89, 300, 625, 2,500, 5,000, and 10,000 $\mathrm{ng} / \mathrm{ml}$ (ITS supplement). Tissues and media were then harvested after $48 \mathrm{~h}$ (when media were changed) and at $96 \mathrm{~h}$. In these studies, we used Costar ultra-low cluster plates (Corning Costar Corporation, 
Cambridge, MA), which had been previously coated with $2 \mathrm{ml}$ of DMEM containing $0.1 \mathrm{mg} / \mathrm{ml} \mathrm{BSA}$ for $20 \mathrm{~h}$ at $37^{\circ} \mathrm{C}$. The combination of these plates and conditions prevented absorption of CPII onto the plastic surface of the well, which otherwise hindered detection in culture medium.

\section{Human cartilage studies}

Human adult femoral condylar OA cartilages from joint replacement were dissected and maintained in Eagle's DMEM medium as described above. They were cut into small pieces $\left(\sim 1 \mathrm{~mm}^{3}\right)$ and randomly mixed and divided into weighed samples of $\sim 50 \mathrm{mg}$ (wet weight) per $1 \mathrm{ml}$ medium per well (24-well plate) as above for culture or for direct analysis. After culture in DMEM, which in this case also contained additional insulin $(1 \mu \mathrm{g} / \mathrm{ml})$, transferrin $(1 \mu \mathrm{g} / \mathrm{ml})$, and sodium selenite $(1 \mathrm{ng} / \mathrm{ml})$ and BSA $(1 \mathrm{mg} / \mathrm{ml})$ with a medium change at 2 and $4 \mathrm{~d}, 25 \mu \mathrm{Ci} / \mathrm{ml}$ of ${ }^{3} \mathrm{H}$-proline was added on day 4 for a further $2 \mathrm{~d}$. Cultures were then harvested and frozen as above.

\section{Half-life of CPII}

To measure the half-life of CPII in bovine fetal cartilages, 24 explant cultures prepared as above were maintained in DMEM without IGF-1 for $10 \mathrm{~d}$. On day 10, all explants were cultured in methionine-free DMEM with $25 \mathrm{ng} / \mathrm{ml} \mathrm{IGF-1} \mathrm{for} 3 \mathrm{~h}$ and then cultured with $50 \mu \mathrm{Ci} / \mathrm{ml}$ ${ }^{35} \mathrm{~S}$-methionine for $2 \mathrm{~h}$ at $37^{\circ} \mathrm{C}$. The explants were rinsed in normal culture media for $15 \mathrm{~min}$. Four wells were harvested (time zero), and the remaining wells were pulse-chased by culturing in methionine-sufficient DMEM for 6, 12, 18, 24, and $36 \mathrm{~h}$. As above, quadruplicate cultures were studied at each time point. These studies were repeated with human normal $(n=1)$ and OA $(n=2)$ femoral articular cartilages.

${ }^{35}$ S-methionine-biolabeled CPII was isolated from cartilage extracts with affinity-purified rabbit antibody to CPII (see below), as described previously (8). $10 \%$ SDS-PAGE was used to analyze the antibody-bound antigens. Autoradiograms of SDS-PAGE gels were analyzed by densitometry. Results were expressed as relative areas of the CPII band equated to $\mathrm{mg}$. wet weight of cartilage.

\section{Extraction of CPII}

To extract CPII and any extractable newly synthesized collagen in cultured cartilages, the cartilages from each well were extracted for $48 \mathrm{~h}$ at $4^{\circ} \mathrm{C}$ with $1 \mathrm{ml} 4 \mathrm{M}$ guanidinium chloride $(\mathrm{GuCl})$ containing the proteinase inhibitors $1 \mathrm{mM}$ EDTA, $1 \mathrm{mM}$ iodoacetamide, $1 \mathrm{mM}$ phenylmethyl sulfonyl fluoride, and $5 \mu \mathrm{g} / \mathrm{ml}$ pepstatin $\mathrm{A}$, in $50 \mathrm{mM}$ sodium acetate, $\mathrm{pH}$ 5.8, and 1\% 3-(3-[(cholamidopropyl)dimethylammonio]-1-propanesulfonate) (CHAPS). Aliquots $(400 \mathrm{ml})$ were then exhaustively dialyzed against $50 \mathrm{mM}$ sodium acetate, $\mathrm{pH} 6.3$, using a microdialysis unit (Bethesda Research Laboratory, Gaithersburg, $\mathrm{MD})$. The volume of the dialysate was measured by weighing so that changes in volume could be accounted for in calculating results.

Uncultured human cartilages were extracted in essentially the same way but after frozen sectioning of the cartilage (see ref. 22).

\section{Tritiated hydroxyproline determination}

This was based on the method used by Tyler and Benton (18). The tissue residue (rinsed with water), dialyzed aliquots of the $4 \mathrm{M} \mathrm{GuCl}$ extracts and lyophilized culture media were hydrolyzed for $18 \mathrm{~h}$ at $110^{\circ} \mathrm{C}$ in sealed glass tubes containing $1 \mathrm{ml} 6 \mathrm{~N} \mathrm{HCl}$. Hydrolyzates were then vacuum-dried, and each was reconstituted in $1 \mathrm{ml} 0.26 \mathrm{~N}$ citrate-phosphate buffer, $\mathrm{pH}$ 3.1. Tritiated hydroxyproline was isolated from an aliquot of the sample on an AG 50W $8 \times 200-400 \mathrm{~m}$ cation exchange resin column $(1.5 \times 7.5 \mathrm{~cm})$ with $0.26 \mathrm{M}$ citrate-phosphate, $\mathrm{pH} 3.1 .361-\mathrm{ml}$ fractions were collected at a flow rate of $0.5 \mathrm{ml} / \mathrm{min}$. Columns were standardized using ${ }^{3} \mathrm{H}$-proline and with hydroxyproline, which was determined colorimetrically (31). Fractions were diluted in scintillation fluid and analyzed for tritium with a Packard CA1900 scintillation counter (Meriden, CT). Approximately 85-90\% of the ${ }^{3} \mathrm{H}$-hydroxyproline was recovered by chromatography, small radiolabeled fragments of collagen having been lost during dialysis of $\mathrm{GuCl}$ extracts and media.

\section{Purification of CPII}

Bovine fetal CPII was purified, and its concentration determined spectrophotometrically as previously described (32). Recombinant human type II procollagen was a generous gift from Dr. A. Fertala and D. Prockop (Allegheny University, Philadelphia). Where indicated it was digested with purified bacterial collagenase (Advance Biofactures Corp., Lynbrook, NY).

\section{Antibodies to CPII}

These studies involved the use of monospecific rabbit antisera to the C-propeptide of bovine type II procollagen. This was prepared as described $(9,32)$. In brief, rabbits were immunized with purified bovine C-propeptide by repeated immunization, starting with Freund's complete adjuvant. The properties of these sera were extremely similar. Very similar results were obtained in all the analyses described here.

\section{RIA assay for CPII}

Assays on cartilage were performed as described previously. Usually purified bovine CPII was used. In some cases, human recombinant procollagen or CPII generated from the latter by bacterial collagenase digestion was studied (11). The $\mathrm{GuCl}$ dialysate $(75 \mu \mathrm{l})$ was diluted in $25 \mathrm{ml}$ of $1 \%$ CHAPS, $2 \mathrm{M} \mathrm{NaCl}, 0.4 \mathrm{M}$ EDTA in $0.4 \mathrm{M}$ potassium acetate, $\mathrm{pH} 7.4$, before assay. For assays of body fluids, the method we described earlier was used (13). Immunoassay revealed that bovine collagen was 10 times more reactive than human CPII: inhibition curves exhibited excellent parallelity (data not shown). A correction factor of $10 \times$ was applied to convert data obtained with bovine CPII to human CPII equivalents for purposes of approximation where results are discussed in terms of total collagen synthesis in human cartilages.

\section{Affinity purification of antibody $R 3233$ for use in immunoprecipitation of CPII}

$1.5 \mathrm{~g}$ amino-hexyl Sepharose (Pharmacia-Upjohn) was washed four times in $0.1 \mathrm{M}$ carbonate, $\mathrm{pH} 9.0$, by briefly centrifuging at $\sim 500 \mathrm{~g}$. It was combined with $8 \mathrm{mg}$ CPII and mixed gently for $24 \mathrm{~h}$ at $4^{\circ} \mathrm{C}$. The column was packed and washed with PBS, followed by $25 \mathrm{ml}$ each of $5 \mathrm{mM}$ Tris, $\mathrm{pH} 7.5,100 \mathrm{mM}$ Tris, $\mathrm{pH}$ 6.7, and $5 \mathrm{mM}$ Tris, $\mathrm{pH}$ 7.5. After rinsing in PBS, $3 \mathrm{ml}$ of rabbit antiserum was added with $2 \mathrm{ml}$ PBS. The column was rocked overnight at $4^{\circ} \mathrm{C}$. It was washed with PBS until the optical density of the elute fell to $<0.02$ OD. The bound antibodies were eluted with $0.1 \mathrm{M}$ glycine $\mathrm{HCl}, \mathrm{pH}$ 3.0. The $\mathrm{pH}$ was immediately adjusted to $\mathrm{pH} 7.0$ by the addition of $2.5 \mathrm{M}$ Tris; $\mathrm{pH}$ 8.0. $\mathrm{E}_{280}$ was used to detect the fractions containing immunoglobulin. These were pooled and concentrated by ultrafiltration with a YM 30 membrane (30-kD cutoff; Millipore, Bedford, MA) to a final volume of $2 \mathrm{ml}$. They were stored at $4^{\circ} \mathrm{C}$.

\section{Distribution with depth of CPII in human articular cartilages}

In a separate study, normal and osteoarthritic human articular cartilages were obtained from autopsy and surgical specimens, respectively. Full-depth blocks $\left(0.5 \mathrm{~cm}^{2}\right)$ were frozen sectioned to produce $20-\mu \mathrm{m}$ thick sections cut parallel to the articular surface from the latter to the deep zone. Groups of five serial sections (100 $\mu \mathrm{m}$ depth) were pooled (20-30 mg) and extracted with $1 \mathrm{ml} 4 \mathrm{M} \mathrm{GuCl}$ for $24 \mathrm{~h}$, at $4^{\circ} \mathrm{C}$ and dialyzed, and CPII was determined by RIA as described (12). The number of $100-\mu \mathrm{m}$ thick levels ranged from 10-25 according to the thickness of the specimens.

\section{Immunoassay of type II collagen content in OA cartilages}

Cartilage was extracted with $\alpha$-chymotrypsin and further solubilized with proteinase $\mathrm{K}$. Total type II collagen content (COL2-3/4m epitope) was measured using these digests by immunoassay as described (3). 
Immunoassay of aggrecan epitopes in body fluids

These were performed for the 846 epitope of aggrecan, a putative marker of synthesis (13) and for a keratan sulfate epitope using a Fab assay as described previously (29).

\section{DNA content of cartilages}

This was determined fluorimetrically (33) on proteinase $\mathrm{K}$ digests prepared as described (3).

\section{Immunohistochemistry of CPII}

CPII was localized using a rabbit polyclonal antiserum to CPII and pepsin-generated $\mathrm{F}\left(\mathrm{ab}^{\prime}\right)_{2}$ in the immunoperoxidase method as described (25). Controls were prepared by preabsorbing the $\mathrm{F}\left(\mathrm{ab}^{\prime}\right)_{2}$ with $100 \mu \mathrm{g} / \mathrm{ml}$ of CPII for $1 \mathrm{~h}$ at $37^{\circ} \mathrm{C}$.

\section{Statistics}

Where indicated, box plots were prepared to show analyses where the upper and lower margins of the boxes represent 75 and $25 \%$ percentiles, respectively. The upper and lower bars represent 90 and $10 \%$ limits, respectively, and the outliers are shown as symbols. Medians are indicated within the boxes. Medians \pm standard deviations are also shown. Spearman rank correlations were performed and analyzed for significance. Mann-Whitney analyses were used to determine significant differences between groups

\section{Results}

Correlation of ${ }^{3} \mathrm{H}$-hydroxyproline synthesis with CPII content in cultured articular epiphyseal cartilages

Bovine studies. CPII was essentially all released from procollagen, as determined by gel electrophoresis and autoradiography of ${ }^{35} \mathrm{~S}$-methionine biolabeled CPII in the half-life experiments (see below), confirming our previous report (14). An average of $5 \%$ of the total ${ }^{3} \mathrm{H}$-hydroxyproline was found in the culture media. Approximately $20 \%$ was present in the $4 \mathrm{M}$ $\mathrm{GuCl}$ extract and the remainder in the tissue residue (data not shown). Data for total tissue and medium contents were combined when determining total ${ }^{3} \mathrm{H}$-hydroxyproline synthesis. There was significant tissue variation in the rate of collagen synthesis, measured as incorporation of ${ }^{3} \mathrm{H}$-proline into hydroxyproline or as CPII. But incorporation into hydroxyproline correlated significantly with the content of CPII determined by RIA. In a representative experiment, the Spearman correlation coefficient was $r=0.848, P=0.0001$ (Fig. $1 A$ ).

Human studies. Cartilages from different osteoarthritic joints were examined to compare the content of CPII with ${ }^{3} \mathrm{H}$-proline incorporation into ${ }^{3} \mathrm{H}$-hydroxyproline. The results of a

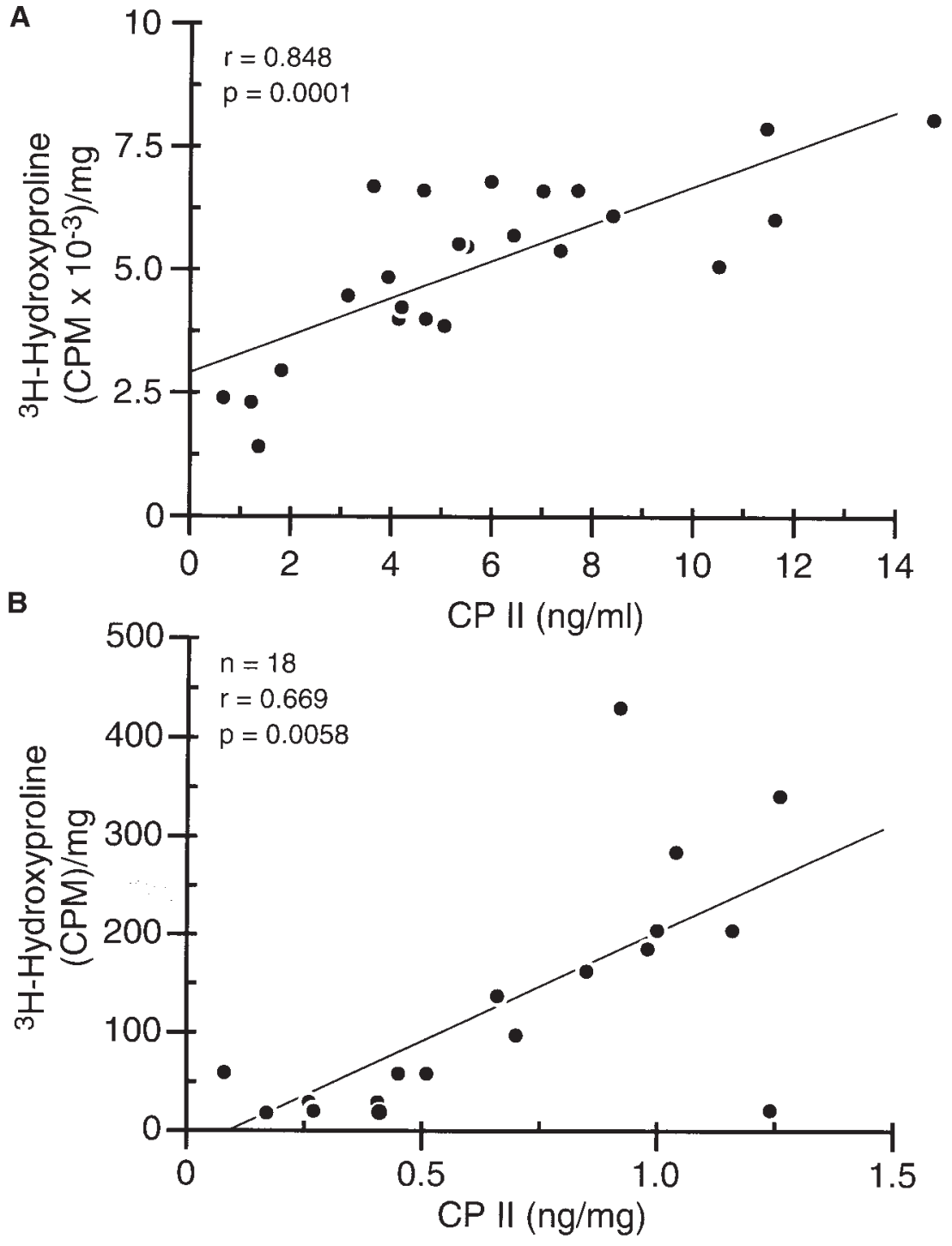

Figure 1. Correlation of type II procollagen synthesis measured by conversion of ${ }^{3} \mathrm{H}$-proline into ${ }^{3} \mathrm{H}$-hydroxyproline vs. C-propeptide content (bovine standard by RIA). Collagen synthesis (A) 24 bovine fetal cartilages + IGF-1 and $(B)$ 18 OA cartilages from a total of five patients (Mankin grade median 5, range 4-8). CPII contents per milligram wet weight are shown. Spearman-rank correlations are shown. Each experimental point represents the mean of combined analyses of four different wells. 
representative experiment on five OA cartilages are shown in Fig. $1 B$. As in the case of the bovine studies, there was a significant correlation between CPII content and ${ }^{3} \mathrm{H}$-hydroxyproline content $(r=0.69 ; P=0.0058)$.

\section{Half-life of CPII in bovine and human cartilages}

The analysis of ${ }^{35} \mathrm{~S}$-methionine-labeled CPII revealed that the radiolabel was predominantly in free CPII removed from procollagen. The data for bovine cartilage is shown in Fig. 2. Similar results were obtained for human cartilages (data not shown). A major band and a secondary minor, faster moving band were observed. The latter represents a natural degradation product lacking 10 residues at the amino terminus (34). Similar results were obtained with the all the antisera (data not shown). There was a progressive reduction of labeled CPII with time (Fig. 2). Densitometric analyses of the main CPII band were made and corrected for total wet weight of cartilage. These revealed that the half-life of fetal bovine CPII was $14.5 \mathrm{~h}$. This was similar to other data obtained from a preliminary experiment $(\sim 16 \mathrm{~h})$. Studies of cartilages from patients with OA revealed half-lives of similar duration, namely $16 \mathrm{~h}$ compared with $14 \mathrm{~h}$ and $19 \mathrm{~h}$ in other experiments (data not shown).

\section{Relationship of CPII content in cartilage to release into culture} medium in bovine studies

Experiments were performed to determine whether CPII released from bovine cartilage reflected the content of CPII within the tissue. Cartilages were cultured in different concentrations of ITS supplement to stimulate variable collagen synthesis.

Analyses of cartilages and culture media, after 48 or $96 \mathrm{~h}$ of culture, revealed a significant correlation between tissue and media contents where $r=0.769, P=<0.0001$ (Fig. 3).

\section{Total contents of CPII in normal and osteoarthritic} human cartilages

Having shown that the content of CPII accurately reflected rates of procollagen II synthesis and that it had a relatively

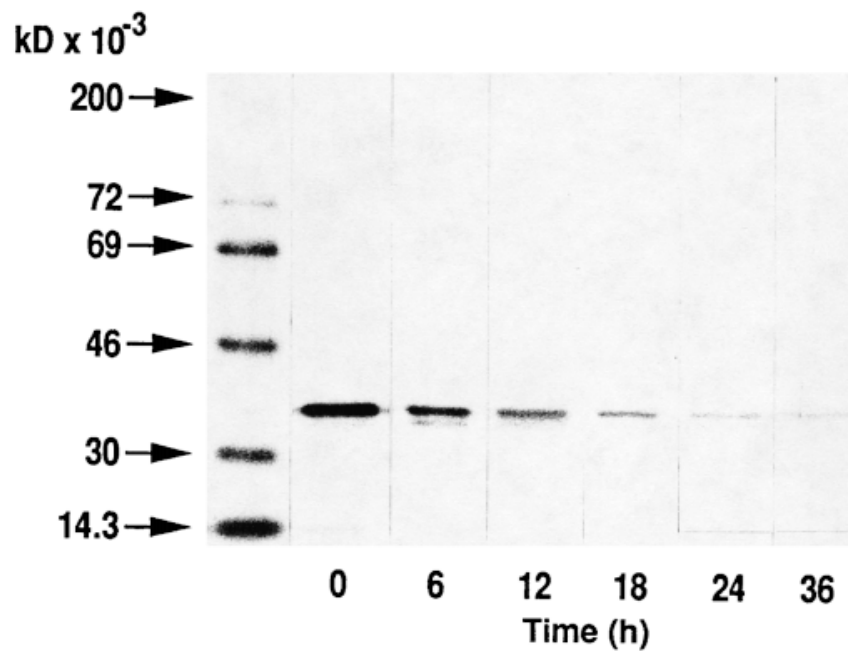

Figure 2. Half-life of C-propeptide in bovine fetal cartilage. SDS-

PAGE autoradiography of immunobound C-propeptide with time after labeling with ${ }^{35} \mathrm{~S}$-methionine. Each experimental point represents the combined analysis of four different wells at the time $(h)$ indicated. Molecular weight markers are shown.

short half-life, we examined the content of CPII in different human articular cartilages. These were maximal in fetal cartilage, being reduced almost threefold at birth and reaching very low levels (mean $3.9 \%$ of newborn) in normal adult cartilage (Table II). But in human OA cartilage, CPII was significantly elevated (mean $3.43 \pm 1.81 \mathrm{ng} / \mathrm{mg}$ ) compared with the normal adult (mean $0.45 \pm 0.27 \mathrm{ng} / \mathrm{mg}$; Table II). This elevation brought the mean content from $3.9 \%$ of that at birth in the normal adult to $29.6 \%$ of the neonatal value in OA cartilage. The elevation was maintained in the more degenerate cartilages, determined by Mankin grade (Table II). There was, however, no correlation in OA cartilages with Mankin grade, as determined by Spearman rank analyses $(r=0.208 ; P=$ $-0.4893)$. The difference in mean CPII content in osteoar-

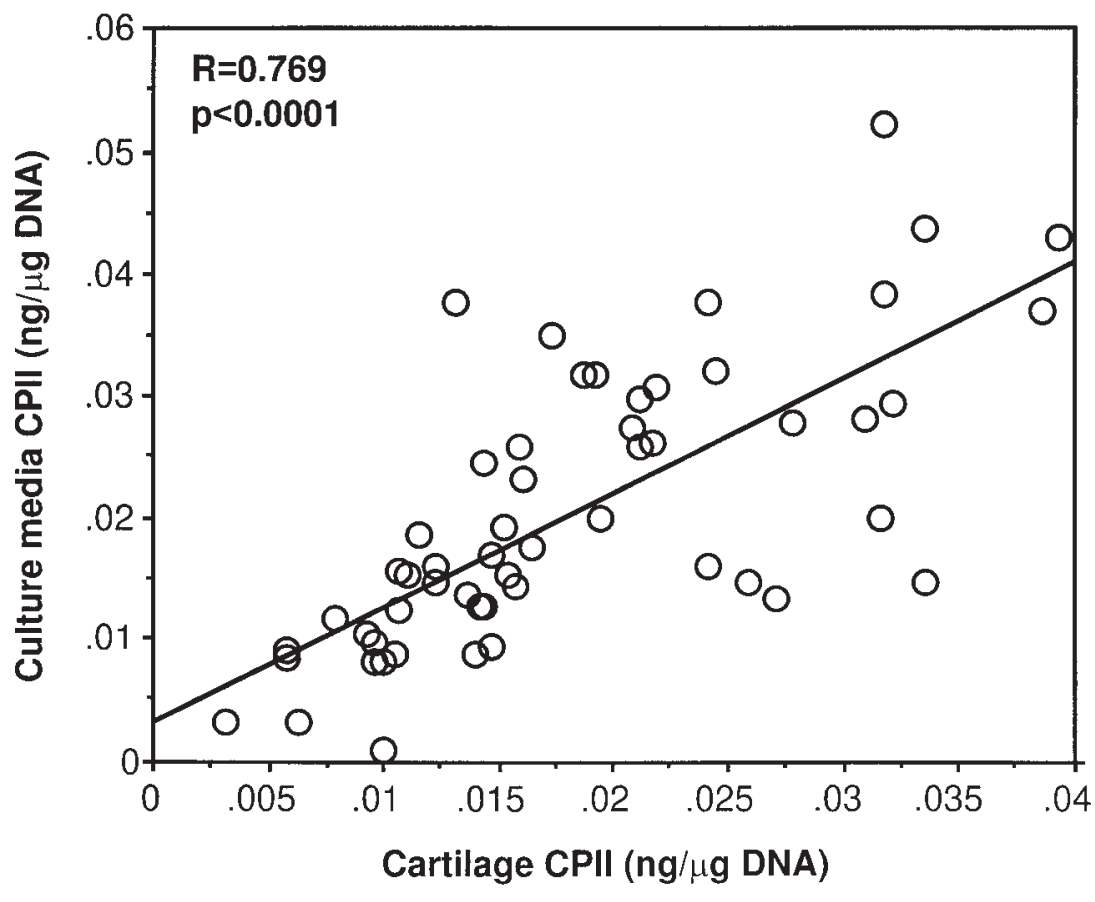

Figure 3. Correlation of CPII content in cartilage with release into culture medium of bovine cultures (CPII by RIA using bovine standard). Each experimental point represents the mean \pm SD of combined analyses of four different wells. 
Table II. Concentrations of the C-Propeptide of Type II Procollagen in Human Articular Cartilages Determined by RIA (Bovine Standard)

\begin{tabular}{|c|c|c|c|}
\hline Group/patient & Age/sample & Mankin grade & C-Propeptide $(\mathrm{ng} / \mathrm{mg}$ wet $\mathrm{wt})$ \\
\hline Fetal $(n=9)$ & $16-18$ wk & - & $33.8 \pm 12.6$ \\
\hline Newborn $(n=2)$ & $0 \mathrm{yr}$ & - & $11.6 \pm 1.5$ \\
\hline Normal & Years & & \\
\hline \multirow[t]{2}{*}{ N1 } & $47 a$ & 0 & $0.38^{*}$ \\
\hline & $47 b$ & 0 & $0.43^{*}$ \\
\hline \multirow[t]{2}{*}{$\mathrm{N} 2$} & $73 \mathrm{a}$ & 3 & $0.37 *$ \\
\hline & $73 b$ & 1 & $1.03^{*}$ \\
\hline \multirow[t]{2}{*}{ N3 } & $79 \mathrm{a}$ & 2 & $0.41 *$ \\
\hline & $79 b$ & 3 & $0.71 *$ \\
\hline N4 & 81 & 1 & $0.28^{*}$ \\
\hline N5 & 79 & 1 & $0.28^{*}$ \\
\hline N6 & 81 & 2 & $0.13^{*}$ \\
\hline \multicolumn{4}{|l|}{ Osteoarthritic } \\
\hline \multirow[t]{2}{*}{ OA1 } & $74 a$ & 2 & $0.89^{\ddagger}$ \\
\hline & $74 b$ & 2 & $0.67^{\ddagger}$ \\
\hline \multirow[t]{2}{*}{$\mathrm{OA} 2$} & $70 \mathrm{a}$ & 2 & $5.79^{\ddagger}$ \\
\hline & $70 \mathrm{~b}$ & 7 & $5.98^{\ddagger}$ \\
\hline \multirow[t]{2}{*}{ OA3 } & $77 \mathrm{a}$ & 9 & $5.70^{\ddagger}$ \\
\hline & $77 b$ & 7 & $1.71^{\ddagger}$ \\
\hline \multirow[t]{2}{*}{ OA4 } & $73 a$ & 10 & $3.57^{\ddagger}$ \\
\hline & $73 b$ & 8 & $3.42^{\ddagger}$ \\
\hline \multirow[t]{2}{*}{ OA5 } & $59 \mathrm{a}$ & 13 & $2.56^{\ddagger}$ \\
\hline & $59 b$ & 10 & $4.26^{\ddagger}$ \\
\hline OA6 & 74 & 5 & $3.64^{\ddagger}$ \\
\hline OA7 & 74 & 6 & $2.96^{\ddagger}$ \\
\hline
\end{tabular}

$\mathrm{a}$ and $\mathrm{b}$ represent two samples from the same condyle. *Mean $\pm \mathrm{SD}$ $0.45 \pm 0.27 ;{ }^{\ddagger}$ mean \pm SD $3.43 \pm 1.81$ significantly different from normal adult $(P<0.0003)$ by Mann-Whitney analysis.

thritic compared with human fetal cartilages $(\sim 9$.9-fold $)$ was of the same order of difference observed between fetal bovine cartilages and human OA cartilages in the radiolabeling studies (Fig. 1).

In a separate study, 50 OA cartilages were analyzed for contents of CPII and total type II collagen. Spearman rank analyses revealed a correlation value of $r=0.3608(P=0.01)$. Thus synthesis appears to be a determining factor in total type II collagen content.

Regional variation in CPII content in human articular cartilages In ageing and OA, changes in articular cartilage can be very localized and regionally quite different. Hence, it was important to determine whether CPII content varied within a femoral condyle in a joint, be it normal or OA. Three pairs of normal cartilage and five pairs of OA cartilages were examined. Specimens were usually $\sim 0.5-1.0 \mathrm{~cm}$ distance from their neighboring samples. In both sets of joints, there was often significant variation in content (Table II).

\section{Variation with depth of CPII in human articular cartilage}

Studies of the distribution with depth of CPII by RIA, revealed that in normal cartilages the small amount that was present was distributed fairly evenly throughout the cartilage. Examples are shown in Fig. 4. In contrast, in OA cartilage of low-moderate Mankin grades, with an intact articular surface, it was usually more concentrated in the mid and deep layers than at the articular surface. Representative examples are shown in Fig. 4.

Immunohistochemical localization of CPII produced similar results. With this method for immunostaining of CPII, this molecule was not detectable in normal cartilages of ages 28 $(n=2), 41,68$, and $69 \mathrm{yr}$, of which an example is shown (Fig. 5 $A)$. In contrast, OA specimens ( $n=16$, age range $52-82 \mathrm{yr}$, mean $68 \mathrm{yr}$ ) always stained strongly, usually in pericellular and territorial sites (Fig. 5, $B$ and $D-F$ ). Specificity of antibody binding was confirmed by the absence of staining in sections treated with nonimmune rabbit $\mathrm{F}\left(\mathrm{ab}^{\prime}\right)_{2}$. Moreover, staining was absent, or considerably reduced, when antibody $\mathrm{F}\left(\mathrm{ab}^{\prime}\right)_{2}$ preparations were preabsorbed with purified CPII (data not shown). In $75 \%$ of OA specimens, staining was restricted to the mid and deep zones (Fig. 5, $C$ and $D$ ). It was usually absent from the natural or new articular surface as we show here. Sometimes, there was staining around chondrocytes throughout most of the cartilage except at the articular surface (Fig. 5 $B)$. In very fibrillated degenerate specimens, intense staining was observed around many chondrocytes, especially where there were clusters of chondrocytes (Fig. 5, $D-F$ ).

\section{Concentrations of CPII in body fluids}

Serum. To determine whether these increases in CPII content were accompanied by increases in serum as we had previously observed in patients with RA (13), we examined CPII content in sera.

Comparisons of sera from patients with OA with those from patients with RA and nonarthritic controls revealed that, whereas CPII was significantly elevated $(P=0.0001)$ in RA, confirming our earlier report for a much smaller group of patients (13), patients with OA exhibited a significant reduction $(P=0.0001)$ in circulating CPII compared with controls (Fig. $6)$. Moreover, the distribution of concentrations was surprisingly narrow and even tighter than that observed in controls. Patients with RA exhibited much more variability in content. There were no correlations in any patient group of CPII to keratan sulfate or 846 epitopes of aggrecan.

\section{$S F$}

In contrast, SF contents of CPII were similar in OA and RA and not significantly different $(P=0.4722$; Fig. 7). Analyses of the ratio of CPII contents in SF to serum of individual patients revealed that CPII was significantly elevated (median 2.05fold) in SF in OA $(P=0.0001)$ but not in RA (Fig. 8), but levels of CPII in SF were not correlated with those in sera in either group. Whereas $89.5 \%$ of patients with OA showed a significant elevation over serum (median $=2.05$ ), only $64.8 \%$ showed an elevation in synovial fluids in RA (median $=1.08$ ).

When levels of CPII in SF were compared with the corresponding CPII contents (mean 1.35 \pm 2.17 ) of single cartilage samples from the same joint at arthroplasty for OA $(n=37)$, we found no evidence of a significant correlation (data not shown).

\section{Correlations between CPII and clinical measurements in} controls, $O A$, and $R A$

In OA, there was an inverse correlation between serum CPII content and disease duration $(r=-0.403, P=0.0157, n=37)$. A relationship of serum CPII to joint pain, which was not quite significant, was also noted $(r=0.327, P=0.06, n=34)$. No re- 
NORMAL CARTILAGES

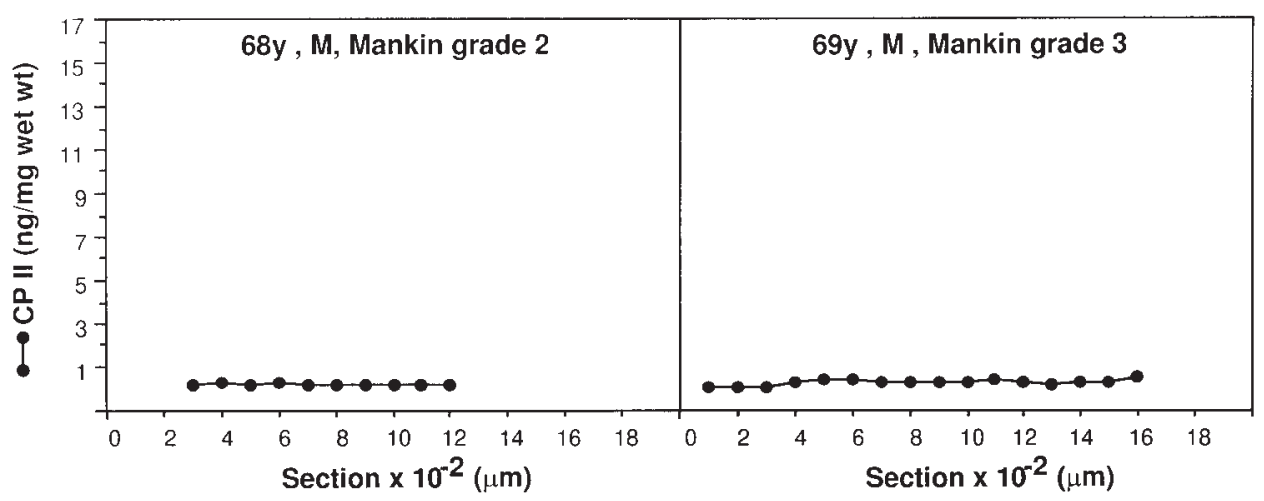

OSTEOARTHRITIC CARTILAGES

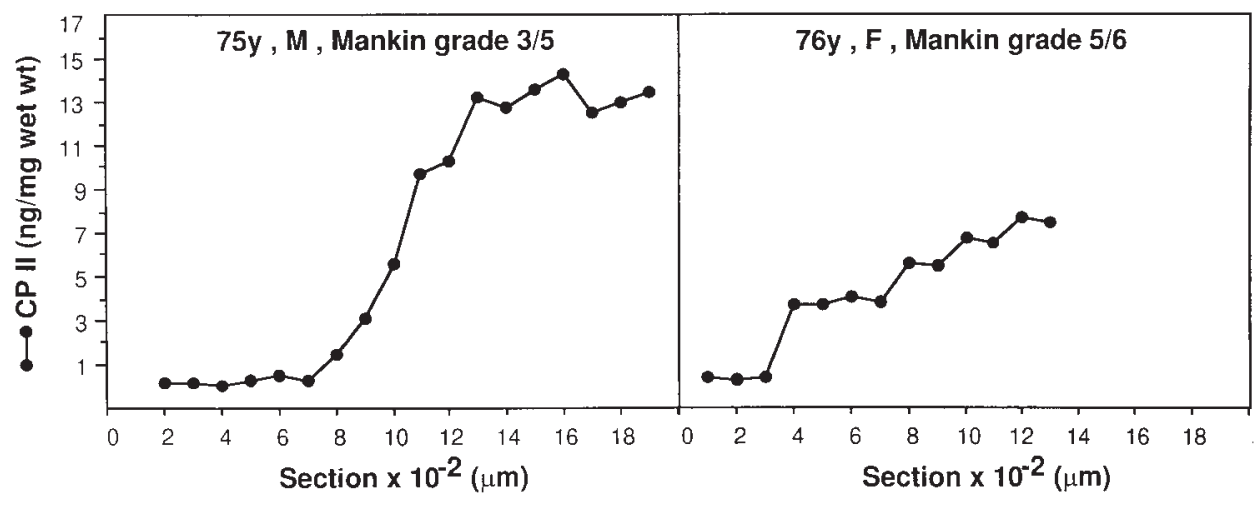

Figure 4. Distribution with depth from articular surface of C-propeptide (by RIA) in representative human normal and osteoarthritic cartilages showing limited degeneration (RIA, bovine standard). Ages, sex, and Mankin grades are also indicated. Means of triplicate assays are shown. lationships were observed to SF white blood cell content, or joint cartilage loss by radiography, or with synovial effusions. There were no relationships in any group, in serum or synovial fluid, to the contents of the keratan sulfate and 846 epitopes of aggrecan.

\section{Discussion}

Recently, we developed new immunochemical methods to study the degradation of type II collagen in OA, both in situ and in isolation $(3,25-27)$. Now, we present an immunological means of studying its synthesis, both in vitro and, for the first time, in vivo, and show that CPII is only transiently present (range $t_{1 / 2}=14-16 \mathrm{~h}$ ) in both fetal bovine and human OA cartilages, at a concentration that directly correlates with the rate of synthesis of the procollagen molecule in these tissues measured in vitro. Moreover, the release of CPII from cartilage in culture directly reflects the rate of synthesis in the tissue. Thus measurement of CPII can be used to study the synthesis of this molecule in vivo and in vitro.

The major advantage of this approach is that by direct analysis of CPII content, we can now examine for the first time synthesis in the patient rather than relying on analysis in vitro, which are subject to changes induced by in vitro culture conditions. Our measurements of synthesis provide quantitative data that can be directly related to biosynthetic rates.

Our studies of development in humans reveal that type II procollagen synthesis is reduced in the newborn from that observed in the fetus and that there is a further major reduction in synthesis in the adult, as previously revealed by SDS-PAGE analyses of CPII in bovine cartilages (35). But in OA articular cartilages, CPII is again often markedly increased. Calculations of how much collagen this increase involves, based on the type II collagen content in OA cartilage (3), as well as the mean CPII content measured in this study, corrected for human CPII (by immunoassay of bovine CPII vs. human recombinant CPII) reveal that in OA cartilages this involves only $\sim 0.01 \%$ of the total collagen measured at a single time point. What is striking from the present study, however, is that this measured synthesis in OA is almost one third of that observed in the very biosynthetically active newborn human articular cartilage.

The direct correlation of synthesis with total type II collagen content also indicates the importance of synthesis in determining collagen content and suggests that the increased synthesis in OA is of importance in maintaining the survival and integrity of the cartilage. Thus, efforts to stimulate synthesis therapeutically should be considered as a strategy in the management of joint damage in OA (see below).

Our studies reveal that although the rate of synthesis is usually very low in healthy cartilage, it is relatively constant throughout the tissue. In OA articular cartilages, exhibiting intermediate degenerative changes, CPII is usually elevated in the middle and deep zones. In more superficial sites, where this increase is often not seen, the degradation of type II collagen is most pronounced $(3,25,27)$. Thus, the more intact (less degenerate) deeper OA cartilage would appear to mount a "reparative" response, characterized by increased synthesis 


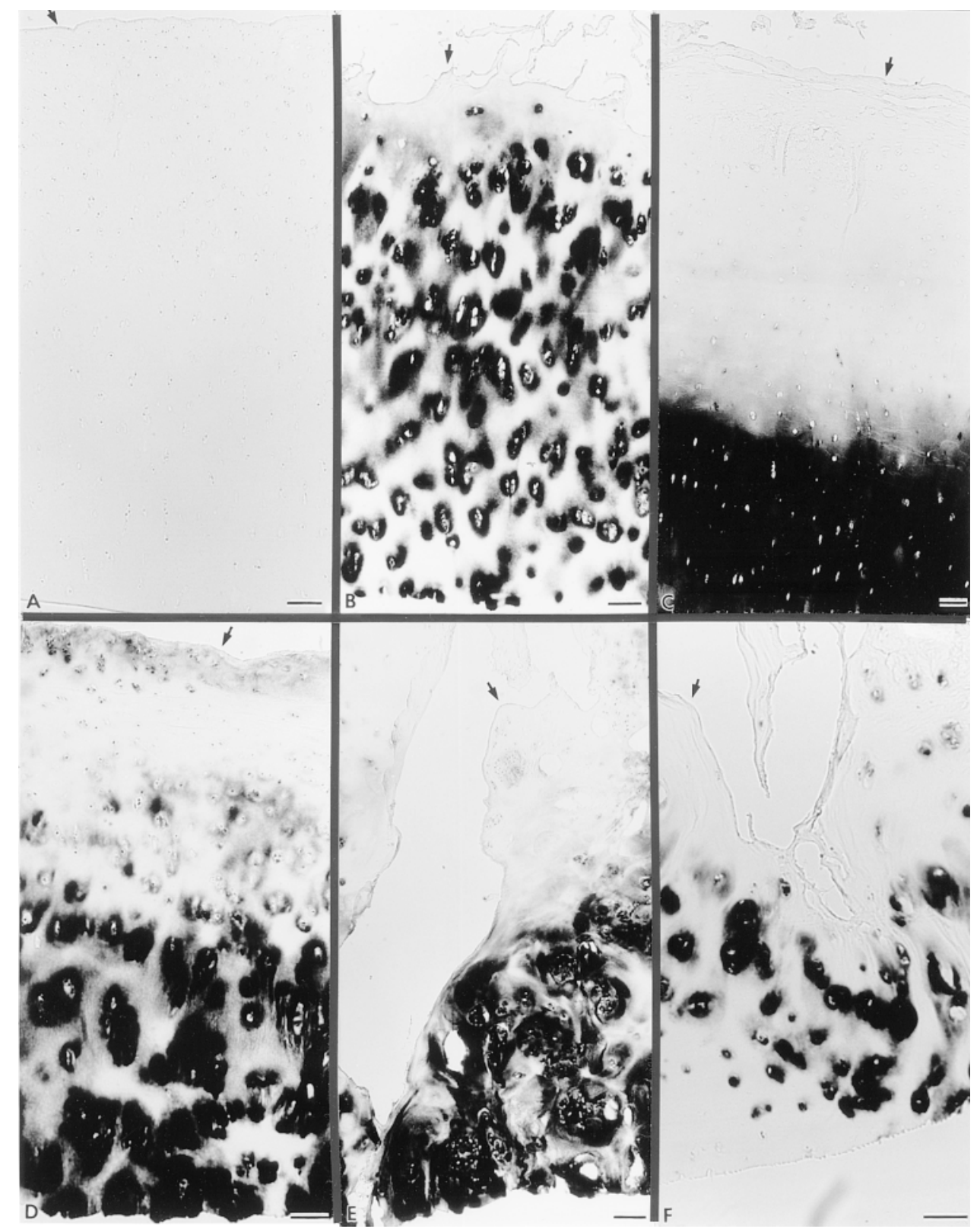

Figure 5. Immunohistochemistry of C-propeptide distribution in representative human $(A)$ normal adult and $(B-F)$ osteoarthritic cartilages. Mankin grades for the whole specimen (not just the area shown) are $A, 0 ; B, 3 ; C, 5 ; D, 7 ; E, 8 ; F, 5$. The articular surfaces are indicated by arrows. Superficial fibrillation is seen in $B$ and $C$, and deep fibrillation is shown in $E$ and $F$. Bars $=$ $100 \mu \mathrm{m}$. of type II procollagen. Even in very degenerate cartilages where type II collagen denaturation is widespread (27), enhanced synthesis was observed throughout the remaining cartilage. Interestingly, in the degenerate human intervertebral disc of the lumbar spine, where we have shown increased denaturation of type II collagen, we have found no evidence from CPII analyses for enhanced biosynthesis of type II procollagen (36). Also, in ageing populations, denaturation of type II collagen is significantly higher in the intervertebral disc than in articular cartilages of the femoral condyles (37). Whether this biosynthetic response in articular cartilages serves to reduce the rate of degeneration of type II collagen in articular cartilage, compared with the lumbar discs, remains to be established.

That CPII is often mainly concentrated around chondrocytes in pericellular and territorial sites in OA cartilages suggests that fibril formation may occur mainly around these chondrocytes, rather than in more remote interterritorial sites.
Even in advanced cartilage degeneration, there was clear evidence for active type II procollagen synthesis, around chondrocytes, especially around clusters or "clones" of cells. There was no indication from the current study that synthesis was reduced in more degenerate cartilages, contrary to an earlier report (22), except at the articular surface where staining was usually absent. This is in agreement with a recent report that revealed a general absence of mRNA expression for this molecule as well as for aggrecan (38) at the articular surface. Nor was there any indication for a reduction in synthesis in the deep zone, in contrast to the reports by Aigner et al. $(23,24)$ who used in situ hybridization. We are, however, in agreement about the low level of synthesis in normal cartilage where only a few cells were positive for $\mathrm{a}_{1}$ (II) procollagen mRNA $(23,24)$. Our new methodology, however, has the advantage in that it directly addresses protein synthesis and avoids possible errors inherent in extrapolations from mRNA data alone, which provides no direct evidence for protein synthesis only for the po- 


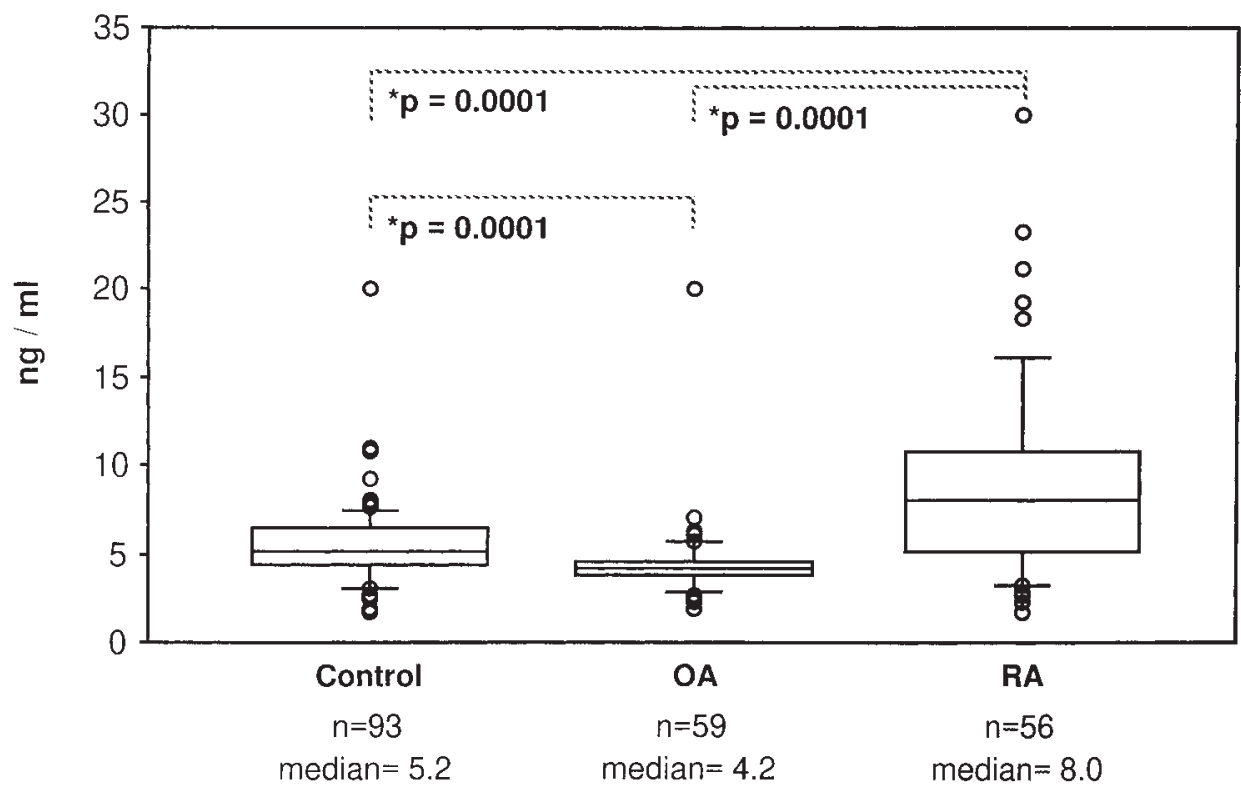

Figure 6. CPII contents (RIA bovine standard) of sera of subjects in control, OA, and RA groups. Significant differences are indicated (each is $P=$ $0.0001)$. tential for synthesis. Clearly, both sets of information complement each other and will, in the future, provide the most valuable insights into our understanding of synthesis at the level of individual cells.

Research in animals has also provided evidence in support of increased procollagen II synthesis in degenerative cartilage. In experimental OA in rabbits, there is a marked increase in total procollagen II synthesis (39). In dogs with natural degenerative disease, there is increased procollagen synthesis early in the disease and a decrease as it progresses (40). Interestingly, this increase was also shown to be accompanied by an increase in procollagen II (41). Moreover, experimental OA in dogs is accompanied by a much more pronounced increase in type II procollagen mRNA for type II collagen than for proteoglycan aggrecan $(42,43)$.

The identification of these increases in type II procollagen synthesis in human and animal articular cartilages, in natural and experimental OA, is especially important because they demonstrate the potential for replacement of damaged collagen fibrils in the extracellular matrix. Since in less damaged cartilage biosynthesis is often enhanced in deeper layers where collagen damage is often less pronounced $(3,27)$, it may be possible, with an appropriate therapeutic approach, to foster this biosynthetic process as well as that involving the proteoglycan aggrecan. Thus, the therapeutic stimulation or enhancement of repair of articular cartilage may be better aimed at preserving and building on this natural repair process. The use of inhibitors designed to arrest collagen degradation may help encourage repair mechanisms.

The observed increase in CPII in diseased articular cartilages in OA was not, however, reflected by an increase in the serum CPII content in OA although the release of CPII from cartilage in culture reflects CPII content in the tissue. This is in contrast to patients with RA where an increase was observed,

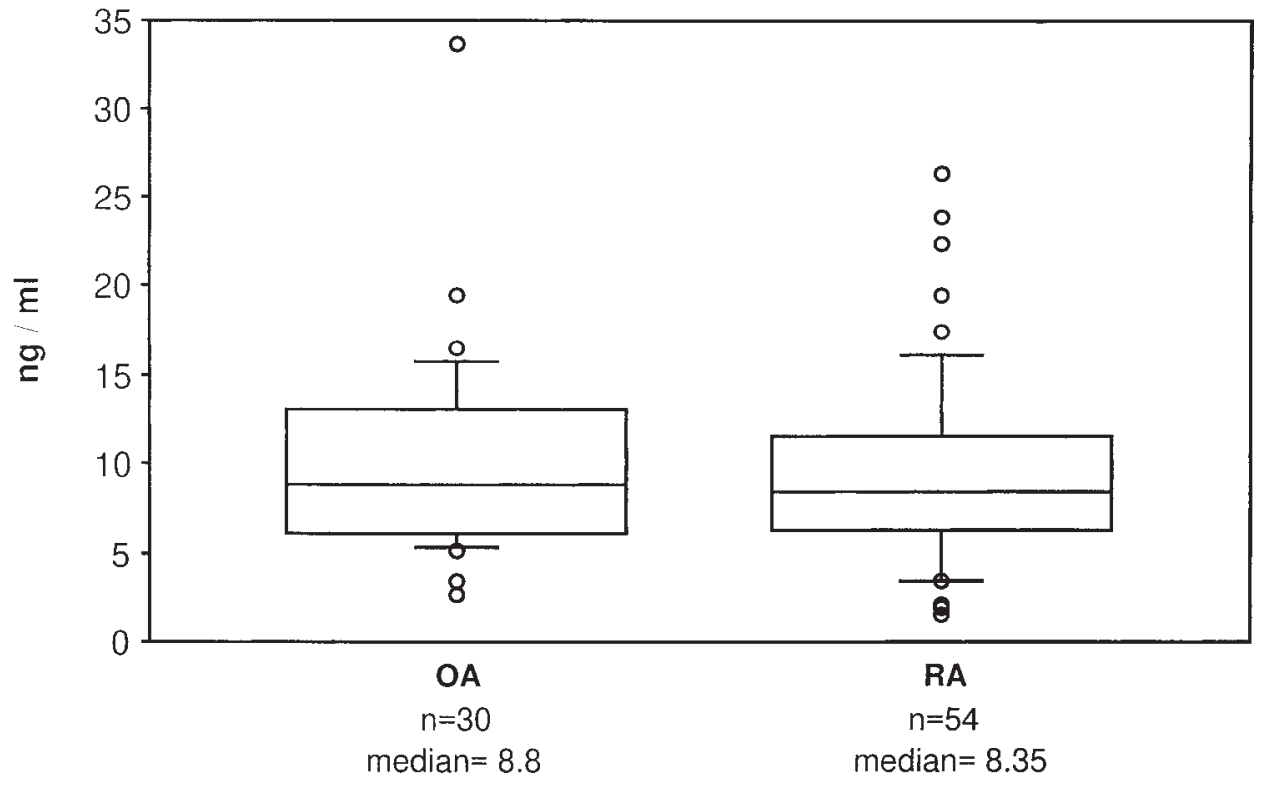

Figure 7. CPII contents (RIA bovine standard) of SF of subjects in $\mathrm{OA}$ and RA subjects. The medians are significantly different $(P=$ $0.0001)$. 


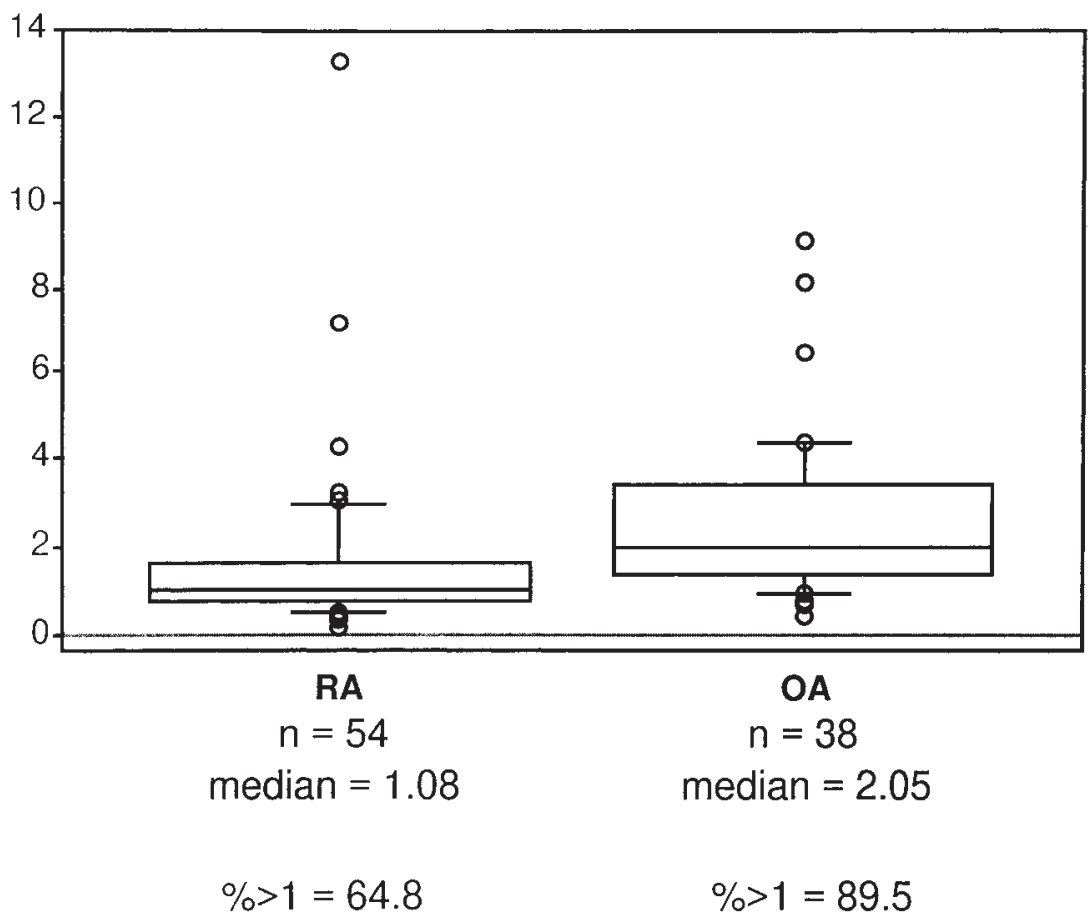

Figure 8. Ratio of CPII contents (RIA, bovine standard) in SF compared with sera measured in the same patient in those with OA and RA. The ratios are significantly different $(P=0.0001)$. as in our previous studies (13) but for which cartilage data was lacking. However, in children CPII is elevated during growth and drops as growth ceases (44). Although a significant increase in CPII in SF over serum was observed in OA compared to RA patients, the elevation over serum levels was small compared with other disease-related epitopes such as the 846 epitope of aggrecan (29). Although an increase in CPII has been reported in OA joint fluid over normal levels (45), there was no evidence in our studies of any overall increase in serum in OA, as observed in RA here and in previous studies (13), or of any correlations between articular cartilage content and joint fluid and serum content of CPII in OA. Thus, the circulating CPII in serum likely reflects whole body cartilage metabolism in OA where few joints are ordinarily involved compared with RA. If this is the case, the decrease in serum CPII in OA may represent reduced synthesis of this molecule within other cartilages. Whether this is a consequence of the disease or causally related to its development remains to be seen.

\section{Acknowledgments}

This study was funded by the Shriners Hospitals for Children, the Medical Research Council of Canada, and the National Institutes of Health (to A.R.P.), the Arthritis and Rheumatism Council (to P.D.), by the National Institutes of Health (to L.R.), the Fonds de la Recherche en Santé du Quebec (to R.C.B.) and by the Swedish Society of Medicine, Wenner-Gren Center Foundation, Swedish Society for Research in Sport Medicine and the Swedish Society of Medicine (to L.D.).

\section{References}

1. Poole, A.R. 1993. Cartilage in health and disease. In Arthritis and Allied Conditions. A Textbook in Rheumatology, 12th ed. D. McCarthy and W. Koopman, editors. Lea and Febiger, Philadelphia. 279-333.

2. Mayne, R. 1989. Cartilage collagens. What is their function, and are they involved in articular disease. Arthritis Rheum. 32:241-246.
3. Hollander, A., T. Heathfield, C. Webber, Y. Iwata, R. Bourne, C. Rorabeck, and A.R. Poole. 1994. Increased damage to type II collagen in osteoarthritic articular cartilage detected by a new immunoassay. J. Clin. Invest. 93: $1722-1732$.

4. Kempson, G.E., H. Muir, C. Pollard, and M. Tuke. 1973. The tensile properties of the cartilage of human femoral condyles related to the content of collagen and glycosaminoglycans. Biochim. Biophys. Acta. 297:456-472.

5. Mow, V.C., L.A. Setton, D.S. Ratcliffe, D.S. Howell, and J.A. Buckwalter. 1990. Structure-function relationships of articular cartilage and the effects of joint instability and trauma on cartilage function. In Cartilage Changes in Osteoarthritis. K.D. Brandt, editor. Indiana University School of Medicine, Ciba-Geigy. 22-42.

6. Prockop, D.J., K.I. Kivirikko, L. Tuderman, and N.A. Guzman. 1979. The biosynthesis of collagen and its disorders. N. Eng. J. Med. 301:13-23.

7. Peltonen, L., R. Halila, and L. Ryhänen. 1985. Enzymes converting procollagens to collagens. J. Cell. Biochem. 28:15-21.

8. Kujawa, M.J., M. Weitzhandler, A.R. Poole, L. Rosenberg, and A.I. Caplan. 1989. Association of the C-propeptide of type II collagen with mineralization of embryonic chick long bone and sternal development. Connect. Tissue Res. 23:179-199.

9. Poole, A.R., I. Pidoux, A. Reiner, H. Choi, and L.C. Rosenberg. 1984. Association of an extracellular protein (chondrocalcin) with the calcification of cartilage in enchondral bone formation. J. Cell Biol. 98:54-65.

10. Lee, E.R., and A.R. Poole. 1996. Ultrastructural localization of the C-propeptide released from type II procollagen in fetal bovine growth plate cartilage. J. Histochem. Cytochem. 44:433-443.

11. Hinek, A., A. Reiner, and A.R. Poole. 1987. The calcification of cartilage matrix in chondrocyte culture: studies of the C-propeptide of type II collagen (chondrocalcin). J. Cell Biol. 104:1435-1441.

12. Alini, M., Y. Matsui, G.R. Dodge, and A.R. Poole. 1992. The extracellular matrix of cartilage in the growth plate before and during calcification in the growth plate before and during calcification: changes in the composition and degradation of type II collagen. Calcif. Tissue Int. 50:327-335.

13. Mänsson, B., D. Carey, M. Alini, M. Ionescu, L.C. Rosenberg, A.R. Poole, and D. Heinegård. 1995. Cartilage and bone metabolism in rheumatoid arthritis. Differences between rapid and slow progression of disease identified by serum markers of cartilage metabolism. J. Clin. Invest. 95:1071-1077.

14. Lee, E.R., Y. Matsui, and A.R. Poole. 1990. Immunochemical and immunocytochemical studies of the C-propeptide of type II procollagen in chondrocytes of the growth plate. J. Histochem. Cytochem. 38:659-693.

15. Nimni, M.E. 1983. Collagen: structure, function, and metabolism in normal and fibrotic tissues. Semin. Arthritis Rheum. 13:1-86.

16. Spanheimer, R.G., and B. Peterkofsky. 1985. A specific decrease in collagen synthesis in acutely fasted, vitamin C-supplemented, guinea pigs. J. Biol. Chem. 260:3955-3962.

17. Spanheimer, R.G., T.A. Bird, and B. Peterkofsky. 1986. Regulation of collagen synthesis and mRNA levels in articular cartilage of scorbutic guinea pigs. Arch. Biochem. Biophys. 246:33-41. 
18. Tyler, J.A., and H.P. Benton. 1988. Synthesis of type II collagen is decreased in cartilage cultured with interleukin 1 while the rate of intracellular degradation remains unchanged. Coll. Relat. Res. 8:393-405.

19. Mankin, H.J., H. Dorfman, L. Lippiello, and A. Zarins. 1971. Biochemical and metabolic abnormalities in articular cartilage from osteo-arthritic human hips. II. Correlation of morphology with biochemical and metabolic data. J. Bone Joint Surg. Am. 53:523-537.

20. Lippiello, L., D. Hall, and H.J. Mankin. 1977. Collagen synthesis in normal and osteoarthritic human cartilage. J. Clin. Invest. 59:593-600.

21. Thompson, R.C., and T.R. Oegema. 1979. Metabolic activity of articular cartilage in osteoarthritis. J. Bone Joint Surg. Am. 61:407-416.

22. Rizkalla, G., A. Reiner, E. Bogoch, and A.R. Poole. 1992. Studies of the articular cartilage proteoglycan aggrecan in health and osteoarthritis. Evidence for molecular heterogeneity and extensive molecular changes in disease. J. Clin. Invest. 90:2268-2277.

23. Aigner, T., H. Stoss, G. Weseloh, G. Zeiler, and K. von der Mark. 1992. Activation of collagen type II expression in osteoarthritic and rheumatoid cartilage. Virchows Arch. B Cell Pathol. 62:337-345.

24. Aigner, T., W. Bertling, H. Stöss, G. Weseloh, and K. von der Mark. 1993. Independent expression of fibril-forming collagens I, II and III in chondrocytes of human osteoarthritic cartilage. J. Clin. Invest. 91:829-837.

25. Dodge, G.R., and A.R. Poole. 1989. Immunohistochemical detection and immunochemical analysis of type II collagen degradation in human normal, rheumatoid, and osteoarthritic cartilages and in explants of bovine articular cartilage cultured with interleukin 1. J. Clin. Invest. 83:647-661.

26. Billinghurst, R.C., L. Dahlberg, M. Ionescu, A. Reiner, R. Bourne, C. Rorabeck, P. Mitchell, J. Hambor, O. Diekmann, H. Tschesche, et al. 1997. Enchanced cleavage of type II collagen by collagenases in osteoarthritic articular cartilage. J. Clin. Invest. 99:1534-1545.

27. Hollander, A.P., I. Pidoux, A. Reiner, C. Rorabeck, R. Bourne, and A.R. Poole. 1995. Damage to type II collagen in ageing and osteoarthritis: starts at the articular surface, originates around chondrocytes, and extends into the cartilage with progressive degeneration. J. Clin. Invest. 96:2859-2869.

28. Arnett, F.C., S.M. Edworthy, D.A. Block, D.J. McShane, J.F. Fries, N.S. Cooper, L.A. Healey, S.R. Kaplan, M.H. Liang, H.S. Luthra, et al. 1988. The American Rheumatism Association 1987 revised criteria for the classification of rheumatoid arthritis. Arthritis Rheum. 31:315-324.

29. Poole, A.R., M. Ionescu, A. Swan, and P.A. Dieppe. 1994. Changes in cartilage metabolism in arthritis are reflected by altered serum and synovial fluid levels of the cartilage proteoglycan aggrecan: implications for pathogenesis. J. Clin. Invest. 94:25-33.

30. Pal, S., L.H. Tang, H. Choi, E. Haberman, L.C. Rosenberg, P.J. Roughley, and A.R. Poole. 1981. Structural changes during development in bovine fetal epiphyseal cartilage. Coll. Relat. Res. 1:151-176.

31. Burleigh, M.C., A.J. Barrett, and G.S. Lazarus. 1974. Cathepsin B1. A lysosomal enzyme that degrades native collagen. Biochem. J. 137:387-398.
32. Choi, H.U., L.H. Tang, T.L. Johnson, S. Pal, L.C. Rosenberg, A. Reiner, and A.R. Poole. 1983. Isolation and characterization of a 35,000 molecular weight subunit fetal cartilage matrix protein. J. Biol. Chem. 258:655-661.

33. Labarca, C., and K. Paigen. 1980. A simple, rapid and sensitive DNA assay procedure. Anal. Biochem. 102:344-352.

34. Van Der Rest, M., L.C. Rosenberg, B.R. Olsen, and A.R. Poole. 1986 Chondrocalcin is identical with the C-propeptide of type II procollagen. Biochem. J. 237:923-925.

35. Niyibizi, C., J.J. Wu, and D.R. Eyre. 1987. The carboxypropeptide trimer of type II collagen is a prominent component of immature cartilages and intervertebral-disc tissues. Biochim. Biophys. Acta. 916:493-499.

36. Antoniou, J., F. Nelson, T. Steffen, N. Winterbottom, A.P. Hollander, A.R. Poole, M. Aebi, and M. Alini. 1996. The human lumbar intervertebral disc: evidence for changes in the biosynthesis and denaturation of the extracellular matrix with growth, maturation, ageing, and degeneration. J. Clin. Invest. 98:996-1003.

37. Hollander, A.P., T.F. Heathfield, J.J. Liu, I. Pidoux, P.J. Roughley, J.S. Mort, and A.R. Poole. 1996. Enhanced denaturation of the a1(II) chains of type-II collagen in normal adult human intervertebral discs compared with femoral articular cartilage. J. Orthop. Res. 14:61-66.

38. Aigner, T.Y., S.I. Vornehm, G. Zeiler, J. Dudhia, K. Von der Mark, and M.T. Bayliss. 1997. Suppression of cartilage matrix gene expression in upper zone chondrocytes of osteoarthritic cartilage. Arthritis Rheum. 40:562-569.

39. Eyre, D.R., C.A. McDevitt, M.E.J. Billingham, and H. Muir. 1980. Biosynthesis of collagen and other matrix proteins by articular cartilage in experimental osteoarthrosis. Biochem. J. 188:823-837.

40. Burton-Wurster, N., C.S. Hui-Chou, H.A. Greisen, and G. Lust. 1982. Reduced deposition of collagen in the degenerated articular cartilage of dogs with degenerative joint disease. Biochem. Biophys. Acta. 718:74-84.

41. Miller, D.R., and G. Lust. 1979. Accumulation of procollagen in the degenerative articular cartilage of dogs with osteoarthritis. Biochim. Biophys. Acta. 583:218-231.

42. Matyas, J.R., M.E. Adams, D. Huang, and L.J. Sandell. 1995. Discoordinate gene expression of aggrecan and type II collagen in experimental osteoarthritis. Arthritis Rheum. 38:420-425.

43. Matyas, J.R., M.E. Adams, D. Huang, and L.J. Sandell. 1997. Major role of collagen IIB in the elevation of total type II procollagen messenger RNA in the hypertrophic phase of experimental osteoarthritis. Arthritis Rheum. 40: 1046-1049.

44. Carey, D.E., M. Alini, M. Ionescu, J.S. Hyams, J.C. Rowe, L.C. Rosenberg, and A.R. Poole. 1997. Serum content of the C-propeptide of the cartilage molecule type II collagen in children. Clin. Exp. Rheum. 15:325-328.

45. Lohmander, S.Y., Y. Yoshihara, H. Roos, T. Kokayashi, H. Yamada, and M. Shinmei. 1996. Procollagen II c-propeptide in joint fluid: changes in concentrations with age, time after joint injury and osteoarthritis. J. Rheumatol. 23: $1765-1769$. 